\title{
Medical Image of the Week: Plastic Bronchitis
}

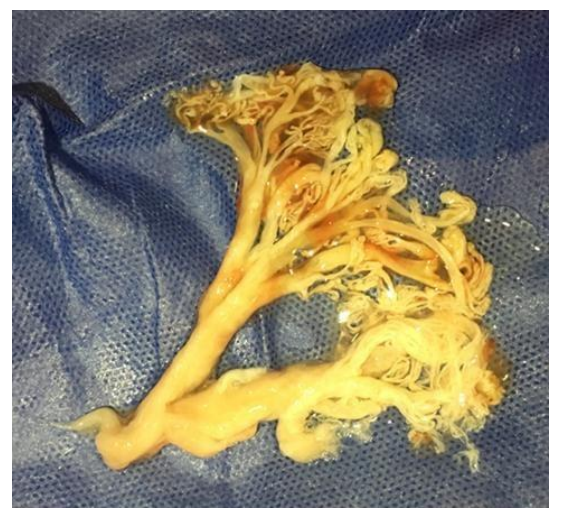

Figure 1. Cast removed from the right main stem.

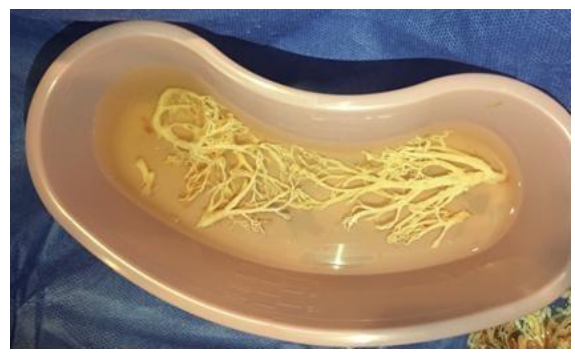

Figure 2. Casts removed from right lower lobe.

Plastic Bronchitis is a rare syndrome characterized with expectoration of bronchial casts. Conditions associated with plastic bronchitis in adults include asthma, allergic bronchopulmonary aspergillosis, cystic fibrosis, bronchiectasis, tuberculosis, amyloidosis, sickle cell anemia and rheumatoid arthritis. In children, is its associated with congenital heart diseases (1).

Typical casts are large and branched. These can be expectorated or removed endoscopically as in our case of a 52-year old man with respiratory failure (Figures 1 and 2). The exact etiology of his plastic bronchitis remains obscure. These casts were removed using a bronchoscope with a cryotherapy probe.

Lauren Estep MD and Bhupinder Natt MD FACP

Division of Pulmonary, Allergy, Critical Care and Sleep

Banner-University Medical Center, Tucson, AZ USA

\section{Reference}

1. Itkin MG, McCormack FX, Dori Y. Diagnosis and treatment of lymphatic plastic bronchitis in adults using advanced lymphatic imaging and percutaneous embolization. Ann Am Thorac Soc. 2016 Oct;13(10):1689-96. [CrossRef] [PubMed] 